\title{
Synthesis of Silver Nano-particles by Electrochemical Method and the Effects on the Serum Levels of Thyroid Hormones (T3, T4) in Adult Male Rats
}

\author{
Zohreh Parang 1(D), Davood Moghadamnia*2 (iD \\ ${ }^{1}$ Department of Physics, Shiraz Branch, Islamic Azad University, Shiraz, Iran. \\ ${ }^{2} \mathrm{PhD}$ of Animal Physiology, Young Researchers and Elite Club, Shiraz Branch, Islamic Azad University, Shiraz, Iran.
}

\begin{tabular}{ll}
\hline Article Info & A B S T R A C T \\
\hline Article Type: & Background: \\
Research & Silver nano-particles have anti-fungal properties. In the present study, silver \\
\hline Article History: & nano-particles were synthesized by electrochemical method and its effects on \\
Received: 19.07 .2019 & the serum levels ofT3 and T4 hormones were investigated in adult male rats.
\end{tabular}

Accepted: 13.10 .2019

\section{* Corresponding Author}

Davood Moghadamnia

PhD of Animal Physiology, Young Researchers and Elite Club, Shiraz Branch, Islamic Azad University, Shiraz, Iran. E-mail: davood.moghadamnia@gmail.com

\section{Methods:}

In this experimental study, 28 adult male Wistar rats weighing approximately 180-220g were divided into 4 groups of 7 rats. The control group (no treatment). The experimental groups 1 and 2 received silver intraperitoneal nano-particle doses of 25 and $100 \mathrm{mg} / \mathrm{kg}$, respectively, for 14 days. The nanoaprticles had been synthesized at 75 seconds interval. The experimental group 3 received silver nano-particles that were synthesized at 300 seconds interval with an intraperitoneal dose of $25 \mathrm{mg} / \mathrm{kg}$ for 14 days. At the end of this period, blood samples were obtained from the rats' hearts, and the serum levels of T3 and T4 hormones were measured. The results were statistically analyzed using ANOVA and Duncan tests.

Results:

At the completion of the study, there was no significant difference in the mean body weights in all experimental groups compared to control group. The results showed that the mean serum levels of T3 hormone in the experimental group1 increased significantly relative to the control group. However, there was no significant difference in the mean serum levels of T4 hormone in all experimental groups compared to that in the control group (P $<0.05$ ).

Conclusions:

Silver nano-particles increased the serum T3 hormone level in male Wistar rats.

Keywords:

Adult Male Rats; Silver Nano-Particles; T3 And T4 Hormones; Thyroid Gland

How to cite this paper:

Parang Z, Moghadamnia D. Synthesis of Silver Nano-particles by Electrochemical Method and the Effects on the Serum Levels of Thyroid Hormones (T3, T4) in Adult Male Rats. Iran J Toxicol.2019;13(4): 21-25

\section{INTRODUCTION}

Silver nano-particles play an important role in science, technology and medicine. The silver nanoscale ranges from 1 to 100 nanometers in diameter. Smaller silver nano-particles enter the cell and react with cellular organelles. Exposure to high doses of silver nanoparticles changes the cellular stress response and initiates cellular messaging cascades that can ultimately lead to the autophagy of the organelles or the whole cell (1). In a study by Ramshini et al. in 2017, nano-silver particles corrected learning and space memory in rats by preventing amyloid fibril-induced neurotoxin toxicity (2). In addition, in a study by
Pereira et al. in 2018, treating rats with silver and titanium nano-particles induced mitochondrial swelling. Exposure of mitochondria to silver and titanium nano-particles reduced the mitochondrial respiration, increased ROS levels, and depleted the endogenous antioxidant system ( $\underline{3})$.

In another study by Kang et al. in 2017, nano-silver particles reinforced the clinical features of atopic dermatitis in mice by activating the mast cells ( $\underline{4}$ ). Also, in the study of Sengstock and collegues in 2014, silver nano-particles corrected osteogenic and adipogenic differentiation in human mesenchymal cells even at non-toxic concentrations ( $\underline{5})$. 
It was also reported by Guang et al. in 2013 that silver nano-particles had molluscicide effects (ㅁ). In another study by Wang et al. in 2013, the silver nano-particles induced RNA polymerase-silver binding and RNA transcription inhibition in erythroid progenitor cells. This study showed that the nano-particles had inhibitory effects on RNA polymerase (). Salem et al. also demonstrated in 2018 that the silver oxide nanoparticles relieve indomethacin-induced gastric ulcer (ㅇ) .

Thyroid is an important endocrine gland that plays a role in regulating the body's metabolism and the functions of bodily organs, including the digestive, heart and reproductive systems. Thyroid disorders are associated with changes in alterations of the proteins and enzymes synthesized by the liver (ㅁ) . Thyroid hormones play important roles in the growth and development of various parts of the brain, especially the hippocampus, subventricular and olfactory bulbs, all of which are involved in learning ( $\underline{10})$. Thyroid stimulating hormone (TSH), secreted from the anterior pituitary, is responsible for the regulation of thyroid hormones synthesis and release. The TSH itself is governed by thyrotropin-releasing hormone (TRH) synthesized by and released from the paraventricular nucleus (11).

Considering the growing application of nano-particles in cancer management and the side effect on the thyroid gland, investigation of the effects of silver nano-particles on the gland is of clinical significance.

\section{MATERIALS AND METHODS}

Synthesis of Silver Nano-particles: In this research, silver nano-particles were produced by electrochemical method in a two-electrode cell, using a Sama 500 electro-analyzer and controlled current coulometry (CCC) systems at room temperature (12). Two plates of platinum were used as cathode and anode. A constant current was applied in a fixed time interval, ranging between 0.001-1 amp and a time interval of 1-65000 seconds. One of the electrodes was static with the other being rotary (speed $=3000 \mathrm{rpm}$ ). The fixed anode electrode was a $2 \times 1 \mathrm{~cm}$ plate. Also, the dimension of the rotating cathode electrode was $0.7 \mathrm{~cm}$. In order to achieve a smooth and clean platinum surface, both electrodes were electrically polished before the experiment.

The electrolyte solution consisted of $5 \mathrm{mM}$ silver nitrate $\left(\mathrm{AgNO}_{3}\right), 0.1 \mathrm{M}$ potassium nitrate $\left(\mathrm{KNO}_{3}\right)$ in double distilled water. To this solution $20 \mathrm{gr} / \mathrm{L}$ polyvinyl pyrrolidone (PVP) was added as the stabilizer. We used a magnetic stirrer to speed up the transfer of synthesized silver nano-particles from the vicinity of the cathodes into the solution and to increase its uniform distribution in the solution (12).

To investigate the toxic effects of silver nano-particles on the liver, we used them in the experiments at two different time intervals, i.e., 75 seconds and 300 seconds. Since, we required ample nano-particles for 14 days of injection, it was necessary to evaluate the shelf-life of the particles over time. Thus, to investigate the sustainability of the particles, we examined the color alteration of the solutions and their spectrum over time.

Animals: All experimental procedures used in this study were approved by the Institutional Animal Care and Ethical Committee of Shiraz Islamic Azad University. We used adult male Wistar rats ( $\mathrm{N}=28), 2.5$ 3 months old and weighing 180-220g. The rats were randomly distributed into four groups of seven each, and kept in standard cages at $20-22^{\circ} \mathrm{C}$ and 12 hours of light/dark cycles, having free access to food and water. In order to adapt the animals to the study conditions, the experiments were conducted several days after the animal adaptation period.

Animal Treatment: The control group received no treatment. The experimental groups 1 and 2 received silver nano-particles at a dose of either 25 or 100 $\mathrm{mg} / \mathrm{kg}$ intraperitoneally for 14 days. The nanoparticles had been synthesized at 75 seconds interval. The experimental group 3 received silver nanoparticles intraperitoneally at a dose of $25 \mathrm{mg} / \mathrm{kg}$ for 14 days. This batch of nano-particles had been synthesized at 300 seconds interval. The doses, duration of treament and route of administration were determined based on the previously established guidelines (13-17).

At the completion of the experimental period, animals were anesthetized by ether, and blood samples were collected from the left ventricle of their heart, and centrifuged at $5000 \mathrm{rpm}$ for 15 minutes. The blood sera were collected and used for the measurement ofT3 and T4 hormones by radioimmunoassay (18).

Statistical Analysis: Data were analyzed by SPSS statistical software, version 22.0 (SPSS Inc., Chicago, IL, USA), and ANOVA and Duncan tests. The statistical inference margin was used to examine the significant differences between the experimental and the control groups. The level of statistical significance was considered at $\mathrm{p}<0.05$ ( (Tables 1-4).

\section{RESULTS}

Since one of the parameters affecting the production of nano-particles was the synthesis time, we noted that the absorption rose with the rising synthesis time. Also, the bright yellow color of the solution at 25 seconds changed to brown color in 300 seconds, which reflects the formation of a high rate of nano-particles or elevation of their synthesis concentration over time (12).

As shown in Figure 1, the color of silver nano-particle solution synthesized at 75 seconds became turbid over time and sediments were formed.

After a few days, a little spectrum widening and relatively low absorption intensity was noted in the absorption spectrum of the nano-particles synthesized at 75 seconds interval. Over time, the color of the nanoparticles produced at one amp current, rotation speed of $3000 \mathrm{rpm}$ and time interval of 300 second, changed from light brown to opaque brown (Fig.2). 


\section{Ag 75}

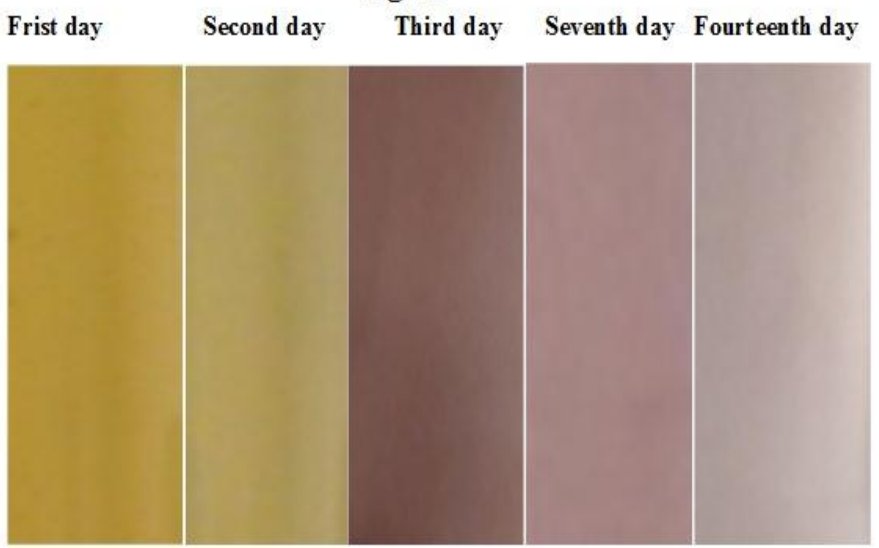

Figure 1. Synthesized silver nano-particles by electrochemical method at different time intervals of 75 seconds in 1 ampere and rotational speed of 3000 seconds in frist, second, third, seventh and fourteenth days (left to right).

\section{$\operatorname{Ag} 300$}

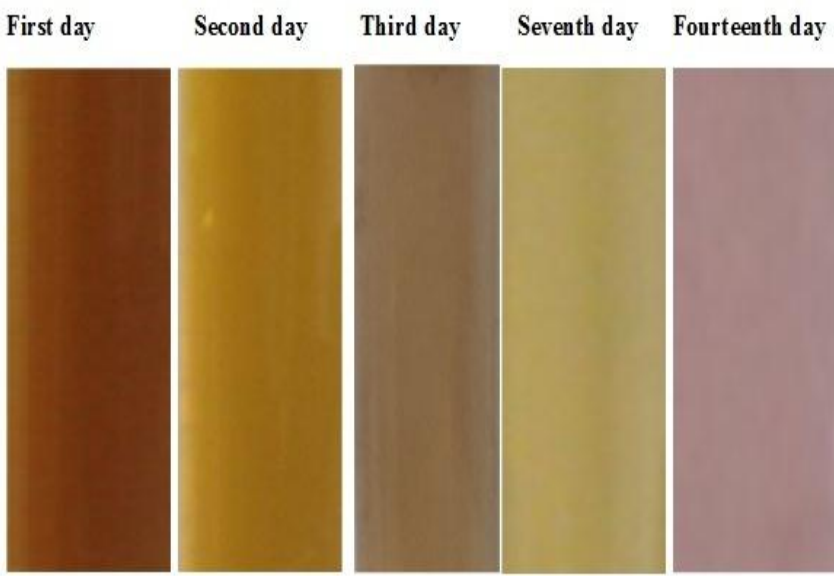

Figure 2. Synthesized silver nano-particles by electrochemical method at different time intervals of 300 seconds in 1 ampere and rotational speed of 3000 seconds in frist, second, third, seventh and fourteenth days (left to right respectively).

The sustainability study of the nano-particles indicated that during the 14-day injection period the absorption intensity of nano-particle's spectrum declined, and some of them precipitated. Therefore, the silver nanoparticles were synthesized daily, and used for the same day's injections. The synthesized silver nano-particles were centrifuged for 15 minutes at $14000 \mathrm{rpm}$. In order to remove added chemicals in the final product, the nano tube was washed three times with distilled water (1ㅡ).

There was no significant difference in the means of the rats' body weight after the experiments among all treatment groups compared to that for the controls (Table 2). The results showed that the mean serum T3 hormone levels for the experimental group 1 increased significantly compared to that for the control group (Table 3). There was no significant difference in the means of serum T4 hormone levels in all of the treatment groups compared to that for the controls $(\mathrm{P}<0.05)$ (Table 4).
Table 1. Comparison of mean body weight before the experiment among the experimental groups receiving silver nano-particles and the control group.

\begin{tabular}{ccc}
\hline All groups & $\begin{array}{c}\text { Number of } \\
\text { samples }\end{array}$ & $\begin{array}{c}\text { body weight before the } \\
\text { experiment (g) }(\bar{X} \pm S E M)\end{array}$ \\
\hline Control group & 7 & $173.5 \pm 0.92$ \\
Experimental group1 & 7 & $183.86 \pm 1.34$ \\
Experimental group2 & 7 & $196.43 \pm 2.37$ \\
Experimental group3 & 7 & $185.00 \pm 4.08$ \\
\hline
\end{tabular}

Values are based on the mean \pm mean error.

Table 2. Comparison of mean body weight after the experiment among the experimental groups receiving silver nano-particles and

\begin{tabular}{ccc}
\hline All groups & $\begin{array}{c}\text { Number of } \\
\text { samples }\end{array}$ & $\begin{array}{c}\text { body weight after the } \\
\text { experiment }(\mathrm{g})(\bar{X} \pm S E M)\end{array}$ \\
\hline Control group & 7 & $181.43 \pm 3.22$ \\
Experimental group1 & 7 & $192.71 \pm 4.88$ \\
Experimental group2 & 7 & $210.71 \pm 4.43$ \\
Experimental group3 & 7 & $196.43 \pm 4.80$ \\
\hline
\end{tabular}

Values are based on the mean \pm mean error.

Table 3. Comparison of mean serum concentration of T3 hormone among the experimental groups receiving silver nano-particles and

\begin{tabular}{ccc}
\multicolumn{3}{c}{ the control group. } \\
\hline All groups & $\begin{array}{c}\text { Number of } \\
\text { samples }\end{array}$ & $\begin{array}{c}\text { T3(ng/ml) } \\
(\bar{X} \pm S E M)\end{array}$ \\
\hline Control group & 7 & $1.20 \pm 0.07$ \\
Experimental group1 & 7 & $1.64 \pm 0.10^{*}$ \\
Experimental group2 & 7 & $1.32 \pm 0.12$ \\
Experimental group3 & 7 & $1.02 \pm 0.03$ \\
\hline
\end{tabular}

* There is a significant difference between the experimental groups receiving silver nano-particles and the control group at the level of $\mathrm{p}<0.05$. Values are based on the means \pm mean errors.

Table 4. Comparison of mean serum concentrations of T4 hormone among the experimental groups receiving silver nano-particles and

\begin{tabular}{ccc}
\multicolumn{3}{c}{ the control group. } \\
\hline All groups & $\begin{array}{c}\text { Number of } \\
\text { samples }\end{array}$ & $\begin{array}{c}\text { T4(ng/ml) } \\
(\bar{X} \pm S E M)\end{array}$ \\
\hline Control group & 7 & $4.43 \pm 0.36$ \\
Experimental group1 & 7 & $4.20 \pm 0.26$ \\
Experimental group2 & 7 & $3.76 \pm 0.32$ \\
Experimental group3 & 7 & $4.78 \pm 0.24$ \\
\hline
\end{tabular}

Values are based on the mean \pm mean error.

\section{DISCUSSION}

In the present study, the effects of silver nano-particles on the serum concentrations of $\mathrm{T} 3$ and $\mathrm{T} 4$ hormones were investigated. The results showed that the mean serum levels of T3 hormone in the experimental group 1 increased significantly relative to that for the control group. However, there was no significant difference in the mean serum levels of T4 hormone in all experimental groups compared to that for the control group. The results of this study were partly consistent with those reported by previous studies (18-21).

In a previous study (20), silver nano-particles at a dose of $150 \mathrm{mg} / \mathrm{kg}$ resulted in a significant increase in the blood level of thyroxine hormones. Also, the concentration of TSH in the groups receiving 50 or $150 \mathrm{mg} / \mathrm{kg}$ silver nano-particles showed a significant decrease compared to that for the sham group ( $\underline{20})$.

In another study (21), it was shown that the oral exposure to a silver nano-particles solution 
significantly increased the $\mathrm{T} 4$ hormone in the experimental groups compared to that for the controls. However, the serum levels of T3 and TSH hormones did not show a significant change among the groups. In a pathological study, no trace of lesions resulting from the exposure to the nanoparticles was observed (21).

Some studies have shown that silver nano-particles impair thyroid function $(\underline{22,23})$. These in vivo and in vitro studies reported that the nano-particles influenced the synthesis pathways of the thyroid hormones. Hinther et al. (24) showed that exposure to silver nano-particles alone lowered the levels of beta receptor variants of thyroid hormones in frogs. Moreover, in a study by Sharifi et al. (25), silver nanoparticles at certain doses in rats led to hyperthyroidism. By increasing the dosage of the nanoparticles, the thyroid gland underwent necrosis and the hormones were significantly altered $(\underline{25})$.

Studies have shown that neurons containing dopamine that originate in the arcuate nucleus are drawn to the hypothalamus, which inhibits the secretion of TRH hormone, especially in the hypothalamus and middle prominence. TRH neurons may have a dual action on prolactin secretion, both through direct effects on lactrotrophs and indirect effects by inhibiting the tuberoinfundibular dopaminergic system. It was found that TRH hormone release, initially stimulated by dopamine, was indirectly inhibited by somatostatin secretion $(\underline{26}, 27)$. Hadrup et al. $(\underline{28})$ found that silver nano-particles at a dose of $9 \mathrm{mg} / \mathrm{kg}$ increased the concentration of 5-hydroxytryptamine. In contrast, the concentration of dopamine in the brain decreased by exposure to silver nano-particles for 14 days. Probably silver nano-particles, by blocking or reducing the synthesis of dopamine, increased the secretion of TRH in paraventricular nucleus of hypothalamus. This subsequently led to an increase in the secretion of TSH from the anterior pituitary, resulting in a rise in $\mathrm{T} 3$ hormone synthesis and release (28).

Also, in a study by Shaheen et al. (29)), it was shown that silver-gold nano-particles corrected the increased insulin levels and glucokinase activity in streptozotocin-induced diabetic rats (29). The nanoparticles lead to increased oxidative stress and reactive oxygen species (ROS), reduced cellular antioxidant such as glutathione, increased cellular involvement in immune processes by damaging the mitochondria. They also damaged the DNA ( $\underline{30})$, leading to the impaired activity of the thyroid gland, which resulted in an increase in T3 hormone release ( $\underline{30})$.

The finding of this study showed that silver nanoparticles led to increased endocrine activity of the thyroid gland. Based on this finding, one of the applications of the new knowledge is the proposal to require periodic clinical examinations and screening of thyroid disorders in patients following the injection of silver nano-particles. This may account for a major preventive approach against the associated disorders.

Limitations: A major limitation of this study was the inability to check histological changes in the thyroid gland. In future cellular and molecular studies, we recommend that the mechanisms of the effect of silver nano-particles on the thyroid gland activity be investigated in future research.

\section{CONCLUSIONS}

This study showed that silver nano-particles increased the serum level of T3 hormone by inducing oxidative stress and increasing reactive oxygen species (ROS), which caused damage to the thyroid gland. Further studies are needed to elucidate the pathological mechanisms involved.

\section{ACKNOWLEDGEMENTS}

The authors sincerely appreciate the support of the Vice Chancellor for Research at Shiraz Azad University. Funding was provided by the Department of Biology, Shiraz Branch, Islamic Azad University, Shiraz, Iran.

\section{CONFLICT OF INTEREST}

There was no conflict of interests in conducting this research.

\section{REFERENCES}

1. Cameron S, Hosseinian F, Willmore W. A current overview of the biological and cellular effects of nanosilver. Intl. Jurnal of Molecular Sciences. 2018;19(7):2030.

2. Ramshini H, Moghaddasi AS, Aldaghi LS, et al. Silver nanoparticles ameliorate learning and spatial memory of male Wistar rats by prevention of amyloid fibril-induced neurotoxicity. Arch. Ital. Biol. 2017;155:131-41.

3. Pereira LC, Pazin M, Franco-Bernardes MF, et al. A perspective of mitochondrial dysfunction in rats treated with silver and titanium nano-particles (AgNPs and TiNPs). Journal of Trace Elements in Medicine and Biology. 2018;47:63-9.

4. Kang $\mathrm{H}$, Kim $\mathrm{S}$, Lee $\mathrm{KH}$, et al. $5 \mathrm{~nm}$ silver nano-particles amplify clinical features of atopic dermatitis in mice by activating mast cells. Small. 2017;13(9):1602363. Doi:10.1002/smll.201602363.

5. Sengstock C, Diendorf J, Epple M, et al. Effect of silver nanoparticles on human mesenchymal stem cell differentiation. Beilstein Journal of Nanotechnology. 2014;5(1):2058-69.

6. Guang XY, Wang JJ, He ZG, et al. Molluscicidal effects of nano-silver biological molluscicide and niclosamide. Chinese Journal of Schistosomiasis Control. 2013;25(5):503-5.

7. Wang Z, Liu S, Ma J, et al. Silver nano-particles induced RNA polymerase-silver binding and RNA transcription inhibition in erythroid progenitor cells. ACS Nano. 2013;7(5):4171-4186. Doi: 10.1021/nn400594s.

8. Salem NA, Wahba MA, Eisa WH, et al. Silver oxide nanoparticles alleviate indomethacin-induced gastric injury: A novel antiulcer agent. Inflammopharmacology. 2018;26(4):1025-35.

9. Malik R, Hodgson H. The relationship between the thyroid gland and the liver. QJM: An International Journal of Medicine. 2002;95(9):559-69. 
10. Bruel-Jungerman E, Davis S, Laroche S. Brain plasticity mechanisms and memory: A party of four. The Neuroscientist. 2007;13(5):492-505.

11. Berne RM, Levy MN, Principles of physiology. St. Louos, MO: Mosby;1998: 910-48.

12. Yin B, Ma H, Wang S, et al. Electrochemical synthesis of silver nano-particles under protection of poly $(\mathrm{N}-$ vinylpyrrolidone). The Journal of Physical Chemistry $B$. 2003;107(34):8898-904.

13. Garcia T, Lafuente D, Blanco J, et al. Oral subchronic exposure to silver nano-particles in rats. Food and Chemical Toxicology. 2016;92:177-87.

14. Sarhan OM, Hussein RM. Effects of intraperitoneally injected silver nano-particles on histological structures and blood parameters in the albino rat. Intl. Journal of Nanomedicine. 2014;9:1505-17.

15. Li TZ, Gong F, Zhang BY, et al. Acute toxicity and biodistribution of silver nitrate and nano-silver with different particle diameters in rats. Chinese Journal of Burns. 2016;32(10):606-12.

16. Rezaei-Zarchi S, Taghavi-Foumani MH, Sheshdeh SA, et al. The effect of silver nano-particles on blood cells in rats. Journal of Biology. 2012;1(1):17-22.

17. Khodarahmi, P. Effect of silver nano-particles on passive avoidance learning in rats, Armaghane-Danesh. 2015;20(6):472-82.

18. Sulaiman AA, Luaibi N, Qassim HA. Effects of silver nanoparticles on thyroid gland structure and function in female rats. Asian J. of Pharmaceutical and Clinical Research. 2018;11(11):509-13.

19. Pani JP, Pani S. Atrophy, Dystosia and Dysmorphic Feature of Mature Thyroid Follicle in 3rd Trimester of Pregnancy- A Disambiguate and Violation Effect of Smallest Size Nan-osilver after Critical Penetration into Its Core. J Clin Trials Regul Aff. 2017;1(1):1-7.

20. Saedi-marghmalki V, Agha-Taheri M. Effect of silver oxide nano-particles on liver enzymes, thyroid hormone and thyroid-stimulating hormone concentrations in rats. $24^{\text {th }}$ Iranian Congress of Physiology and Pharmacology. Tehran, Iran. 2015;2-12.
21. Rejali L, Moshtaghian SJ, Mahzouni P, et al. The effect of chronic consumption of silver nano-particles on thyroid gland and pregnancy in rats. Qom Univ Med Sci J. 2015;9(7):20-8.

22. Lavado-Autric R, Ausó E, García-Velasco JV, et al. Early maternal hypothyroxinemia alters histogenesis and cerebral cortex cytoarchitecture of the progeny. The Journal of Clinical Investigation. 2003;111(7):1073-82.

23. Ausó E, Lavado-Autric R, Cuevas E, et al. A moderate and transient deficiency of maternal thyroid function at the beginning of fetal neo-corticogenesis alters neuronal migration. Endocrinology. 2004;145(9):4037-47.

24. Hinther A, Vawda S, Skirrow RC, et al. Nanometals induce stress and alter thyroid hormone action in amphibia at or below North American water quality guidelines. Environmental Science \& Technology. 2010;44(21):831421.

25. Sharifi, AS, Naseri S, Rezaei Zarchi S, et al. Effect of silver nano-particles on thyroid hormones and tissue in male rat. $1^{\text {st }}$ National Conference on Nano Sience and Technology. 2010;1-340.

26. Maeda K, Frohman LA. Release of somatostatin and thyrotropin-releasing hormone from rat hypothalamic fragments in vitro. Endocrinology. 1980;106(6):1837-42.

27. Sugden MC, Fryer LG, Priestman DA, et al. Increased hepatic pyruvate dehydrogenase kinase activity in fed hyperthyroid rats: studies in vivo and with cultured hepatocytes. Molecular and Cellular Endocrinology. 1996;119(2):219-24.

28. Hadrup N, Loeschner K, Mortensen A, et al. The similar neurotoxic effects of nanoparticulate and ionic silver in vivo and in vitro. Neurotoxicology. 2012;33(3):416-23.

29. Shaheen TI, El-Naggar ME, Hussein JS, et al. Antidiabetic assessment; in vivo study of gold and core-shell silvergold nano-particles on streptozotocin-induced diabetic rats. Biomedicine \& Pharmacotherapy. 2016;83:865-75.

30. Xu L, Li X, Takemura T, et al. Genotoxicity and molecular response of silver nanoparticle (NP)-based hydrogel. Journal of Nanobiotechnology. 2012;10(1):16. 